\title{
O drama de Camilo Castelo Branco em ação
}

\author{
Milca Tscherne ${ }^{1}$
}

\begin{abstract}
RESUMO: Este artigo é uma reflexão sobre o desafio formal de Luiz Francisco Rebello para criar uma linguagem, em seu teledrama Todo o amor é amor de perdição, tão ao estilo camiliano a ponto de tornar turva a distinção entre a sua inscrição autoral e os trechos insertos do próprio Camilo Castelo Branco, mostrando que a absorção não foi somente dos textos, mas do estilo do romancista português.
\end{abstract}

ABSTRACT: This article presents thoughts about the formal challenge faced by Luiz Francisco Rebello to create a language in his TV drama Todo o amor é amor de perdição so close to Castelo Branco's style to the point of confusing Rebello's language with inserted texts originally written by Camilo Castelo Branco. In doing this, one reveals that there was assimilation of texts and style of the Portuguese novelist.

PALAVRAS-CHAVE: Dramaturgia; Teatro português; Luiz Francisco Rebello; Camilo Castelo Branco

KEYWORDS: Dramaturgy; Portuguese theater; Luiz Francisco Rebello; Camilo Castelo Branco

\section{Introdução}

Todo o amor é amor de perdição afigura-se como a primeira proposta teledramática de Luiz Francisco Rebello (n.1924). O teledrama trata do julgamento do escritor português romântico Camilo Castelo Branco e de sua amante Ana Augusta Plácido que, presos, respondem pelo crime de adultério. O teledrama reporta-se também, de modo sumário, ao futuro do casal em São Miguel de Seide para acompanhar a trajetória de Camilo até sua morte.

\footnotetext{
${ }^{1}$ Doutoranda do Programa de Estudos Literários da UNESP de Araraquara. Linha de pesquisa: Teoria e crítica do drama. Título da pesquisa: "Por um teatro novo em Portugal: a contribuição de Luiz Francisco Rebello".
} 
Foi exibido pela RTP (Rádio e Televisão Portuguesa) em 1990, publicado como dramaturgia em 1994 e premiado em 1996 pela Sociedade Portuguesa de Autores.

O texto conserva, naturalmente, algumas peculiaridades de um drama criado para ser exibido pela televisão, como, por exemplo, indicação de falas em off, para mostrar os momentos em que a imagem não coincide com o som, mudanças velozes e numerosas de espaço e, consequentemente, de cenas também.

\section{Apresentação dos "dramas" camilianos}

Luiz Francisco Rebello, como dramaturgo experiente, não pôde deixar de captar o potencial dramático da figura romântica do escritor Camilo Castelo Branco. Tomando o termo em sua dupla acepção, Camilo é, por excelência, dramático. Dramático, em seu uso mais corrente e consagrado pela acepção popular do termo, em função de suas mazelas pessoais: bastardia, orfandade, prisão, doenças e suicídio. E dramático, em seu sentido mais próprio, figura que guarda em si não só o poder da ação teatral, mas uma consciência teatral que pode ser conferida até nas suas últimas palavras escritas na carta de despedida que deixou.

Para compor Todo o amor é amor de perdição, Rebello trabalha a figura do escritor, do homem e do amante Camilo Castelo Branco em diálogo com algumas de suas obras, elegendo como destaque o episódio que the rendeu a novela passional mais conhecida do romantismo português, Amor de perdição, escrita durante o período em que esteve preso e, $O$ último ato, peça de Camilo cujo conteúdo levou Rebello a considerá-la o drama que mais traços biográficos apresenta acerca do escritor romântico.

A peça de Rebello é, portanto, uma obra sobre Camilo, calcada essencialmente nas palavras escritas e dramatizadas por ele mesmo, numa autobiografia que foi sendo construída e representada em seus mais diversos escritos. 
O primeiro aspecto importante a se destacar é a opção Rebello, não por acaso a mesma de Camilo Castelo Branco, no processo de composição de personagens. Ambos, para agudizar a dimensão trágica de suas personagens, as apresentam não só como verossímeis, mas também como verídicas.

Em Amor de perdição, por exemplo, o narrador, que induz o leitor a pensar ser ele também o autor, descreve o degredo de "seu" tio paterno Simão Botelho, condenado, aos dezoito anos, por amar quem não deveria. Faz questão de esclarecer, logo no início da narrativa, que ao ler o nome do parente no livro de assentamentos da Cadeia da Relação, ou seja, a partir de documentos, decide escrever sobre sua vida, cuja história coincide, no momento de escritura, com a do próprio narrador. Tio e sobrinho que não chegaram a se conhecer, salvo por meio das histórias contadas pelos parentes, têm em comum o cenário da cadeia e um amor condenado.

A narrativa perde, à medida que vai se construindo, um pouco desta ancoragem verídica. No entanto, ao final, ela é resgatada para a "veracidade dos fatos". O narrador situa o momento presente, usando para isso uma linguagem que consolida a ideia de um relato verídico que chegara ao fim, preocupando-se inclusive em atualizá-lo na $5^{\mathrm{a}}$ edição. Eis a explicação inserida:

Da família de Simão Botelho vive ainda, em Vila-Real de Trás-os-montes, a senhora D. Rita Emília da Veiga Castelo Branco, a irmã predileta dele(*). A última pessoa falecida, há vinte e seis anos, foi Manuel Botelho, pai do autor deste livro.

FIM

$\left({ }^{*}\right)$ Morreu em 1872 (Nota da $5^{\mathrm{a}}$ edição) (CASTELO BRANCO, 1943, p. 249-259)

O nome completo do pai de Camilo Castelo Branco era Manuel Joaquim Botelho Castelo Branco. De fato, o narrador incita, quem quer que seja, a fazer uma leitura biográfica da novela. Em função do contexto do autor, a história imaginada por ele acerca do tio recebe 
elementos extremamente verídicos, que estabelecem pontos de contato com a história paralela, que ele próprio está vivendo, inclusive habitando o mesmo cenário.

Para escrever Todo o amor é amor de perdição, Luiz Francisco Rebello concentra-se em tais curiosidades, parte de um Camilo humano, cuja história é bem conhecida, entendida como verídica e rica em documentos oficiais. Consegue com isso recompor o contexto de escritura de Amor de perdição, que também partiu do documental. Ambos, Camilo e Rebello, folhearam os livros de antigos assentamentos no cartório da Cadeia da Relação do Porto e encontraram, no das entradas dos presos, registros de prisão e julgamento de pessoas que lhes inspirariam ficção.

Rebello encontrou Camilo absolvido. Camilo, ao contrário, encontrou seu tio Simão condenado ao degredo, que não chegou a cumprir por morrer em pleno mar a caminho de sua pena.

Embora Camilo não tenha sido punido com o degredo, tampouco morto na ocasião próxima nem posterior ao adultério, como acontecera com Simão Botelho, Rebello opta por apresentar cenicamente Camilo até a sua morte em mais uma aparente tentativa de aproximar-se do estilo camiliano de composição de personagens trágicas.

Outra fonte inspiradora para Rebello, como dramaturgo que é, foi a carta escrita por Camilo momentos antes de suicidar-se, pois a carga de dramaticidade posta ali é fácil de ser visualizada na boca de um ator ou fixada como uma réplica num texto dramático tal como ele a escreveu. Ela não foge ao estilo camiliano como escritor de ficção nem como o de dramaturgo. Sua densidade dramática está incorporada ao teledrama de Rebello que apresenta o mesmo tom grave, dramático, marcado por gradações, por revelações, por constatações temporais e existenciais concisas na justificação do adeus à vida.

22 de novembro de 1886. 10 horas da noite. Os incuráveis padecimentos que vão complicando os dias levam-me ao suicídio - único remédio que lhes posso dar. Rodeado de infelicidade de espécie moral, sendo a 
primeira a insânia de meu filho Jorge, e a segunda os desatinos de meu filho Nuno, nada tenho a que ampare nas consolações da família. A mãe desses dois desgraçados não promete longa vida; e, se eu pudesse arrastar a minha existência até ver Ana Plácido morta, infalivelmente me suicidaria. Não deixarei cair sobre mim essa enorme desventura, a pior, a incompreensivel à minha incompreensão da desgraça.

Previ, desde os 30 anos este fim. Receio que, chegando o supremo momento, não tenha firmeza de espírito para traçar estas linhas. Antecipo-me à hora final. Quem puder ter a intuição das minhas dores, não me lastime. A minha vida foi tão extraordinariamente infeliz que não podia acabar como a maioria dos desgraçados. Quando se ler este papel, eu estarei gozando a primeira hora de repouso. Deixo um exemplo. /este abismo a que me atirei é o término da vereda viciosa por onde as fatalidades me encaminharam. Seja bom e virtuoso o que puder ser. Camilo Castelo Branco, São Miguel de Seide. (Apud CAMOCARDI, 1973, p52)

Por ter esta natureza híbrida, permeada por biografia e ficção, Todo o amor é amor de perdição requisita uma leitura que considere a relação entre a vida e a obra do escritor Camilo Castelo Branco, uma vez que Rebello a primou como eixo composicional.

Ademais, a abordagem de conciliar vida e obra do escritor romântico prestigia também a leitura da tradição que, não sem razão, sempre teve a tendência de conjugar biografia e novelística camilianas.

E parece lícito acreditar que, não fora a dimensão trágica de sua vida, a sua obra não ganharia a espantosa perspectiva humana que a torna num complexo, denso e desconcertante estudo da substância amarga, e todavia, sublime, de que o homem é feito.(MENDONÇA, 1971, p. 5)

Por serem elas indiscutivelmente parecidas, o estudioso Fernando Mendonça chega a ponto de condicioná-las a certo grau de dependência mútua. Por certo as tensões íntimas e sociais da vida do escritor romântico contribuíram em sua atividade criadora, influenciaram-no na elaboração dos conflitos humanos e deram-lhe uma percepção fatídica da existência que tão insistentemente se apresenta em sua obra. 


\section{Apresentação de Todo o amor é amor de perdição}

Dividido em três partes, a primeira que compõe o teledrama começa no palco do Teatro Nacional. Uma peça do escritor Camilo Castelo Branco intitulada $O$ último ato está sendo encenada. Mas o telespectador só percebe ser uma representação após algumas réplicas, quando as câmeras recuam e mostram a boca de cena e o público do teatro.

Adiante, as câmeras fixam-se num telespectador que demonstra nervosismo e muita atenção ao espetáculo. Seu nome é Manuel Pinheiro Alves, 52 anos, marido de Ana Augusta Plácido, amante do escritor Camilo Castelo Branco. Ao se lado, está o amigo Agostinho Velho, 58 anos.

O diálogo no palco continua com as vozes dos atores em "off". Em seguida, as câmeras passam para um segundo plano e recaem sobre Pinheiro Alves que, furioso, entende que aquele espetáculo é uma provocação pública de Camilo que, mesmo preso e aguardando julgamento pelo crime de adultério, conseguiu levar à cena seu espetáculo. Quando Pinheiro Alves começa a reclamar, de imediato os espectadores pedem que se controle. Sua indignação é em razão de ter se visto no palco, na figura do marido traido, e de reconhecer sua tragédia pessoal exposta pelo seu próprio algoz, Camilo, que lhe humilha agora duplamente.

Num deslocar de câmeras, os atores que estavam representando Antônio José plácido, pai de Ana Plácido, Pinheiro Alves, o marido, e Ana Plácido são substituídos pelos próprios representados, embora se continue a ouvir as vozes daqueles.

Neste momento, justifica-se porque Pinheiro Alves, quando estava na plateia, foi privilegiado pelo "olhar" da câmera que o isolou, para em seguida alçá-lo até o palco e inseri-lo no espetáculo. A seqüência se dá em paralelo. Ora são os atores do drama de Camilo, ora Pinheiro Alves e as demais personagens da trama de Rebello que interpretam seu próprio papel. 


\section{Sobre $O$ último ato e a incorporação do estilo camiliano por Rebello}

Camilo Castelo Branco elabora sua dramaturgia paralelamente a seus romances. Foi em 1846, com o drama histórico Agostinho de Ceuta, que, aquele que viria a ser um romancista por profissão, estreou dramaturgicamente, antes mesmo de publicar seu primeiro romance Anátema.

O último ato presente no teledrama de Rebello é, de fato, um de seus dramas, portanto, não é criação de Rebello enquanto texto dramático. Considerado dentre sua numerosa literatura dramática o mais autobiográfico (Rebello, 1991, p. 83) é inserido, evidentemente em função disso, em Todo o amor é amor de perdição.

O teledrama é iniciado com a cena II de $O$ último ato que se estende, com poucos cortes, até parte da cena $\mathrm{V}$, quando a imagem dos atores que representam o drama de Camilo é substituída pelas imagens dos personagens que protagonizam o teledrama de Rebello.

Esta peça de Camilo Castelo Branco apresenta um conflito baseado num triângulo amoroso que conduz a jovem D. Ana Augusta à morte. A protagonista, casada por conveniência com um homem mais velho, jamais conseguiu esquecer seu grande amor, Jorge, de quem recebe uma carta suicida, cujo conteúdo a faz cair enferma e, agonizando, revela que a morte será o seu refúgio de punição e de redenção ao mesmo tempo.

Como já mencionado, $\mathrm{O}$ último ato apresenta-se ora em alternância, ora em paralelo com o conflito de Todo o amor é amor de perdição. Como teatro é signo, não parece uma temeridade desenvolver uma interpretação - sempre motivada e orientada pelo eixo vida/obra - que $O$ último ato é um recurso de estrutura que propõe acentuar, por meio de um confronto especular sugerido pela peça de Camilo dentro da peça de Rebello, a relação que Camilo estabelecia com o seu universo ficcional, no qual traços biográficos permeavam a ficção. 
O que chama atenção nessa laboriosa articulação entre as correspondências de situações e personagens sugeridas pelo teledrama, nesse jogo de espelho entre a vida e a ficção de Camilo, acentuada pela proposta metateatral do teledrama, é a homogeneidade estilística de Rebello perceptivel na superficie de um texto dramático que foi composto a partir de tantos textos.

Não há qualquer estranhamento de estilo na transição do texto de Camilo Castelo Branco para o texto de Luiz Francisco Rebello, textos estes que se mesclam, sobretudo, na primeira parte do teledrama onde cenas d' O último ato são insertas nas réplicas de Rebello.

\section{Conclusão}

Amor de perdição, O último ato, Memórias do cárcere, a carta de despedida de Camilo constituem as escolhas de Rebello para compor, entrelaçar e sustentar harmonicamente a dupla inscrição autoral de Todo o amor é amor de perdição.

Tal arranjo explicita de que modo o desafio formal de Rebello desenvolveu-se desde o processo de composição de personagem, à percepção de ritmo de escritura, de gradação de Camilo, até a absorção de seu estilo a ponto de produzir homogeneidade, ausência de ruptura e fluência ao teledrama.

Para além da comparação e das semelhanças que Luiz Francisco Rebello conseguiu travar com o estilo trágico-romântico de Camilo Castelo Branco percebemos a homenagem que o moderno dramaturgo português fez ao Camilo dramaturgo.

Pouquíssimo conhecida, a dramaturgia de Camilo Castelo Branco comporta vinte e seis textos de teatro. Em 2001, ou seja, dez anos depois de Todo o amor é amor de perdição, Luiz Francisco Rebello seleciona e publica três peças de Camilo. Oficialmente a apresentação é feita no prefácio da obra: 
Entre o romancista genial e o poeta medíocre que foi Camilo, mas sem dúvida bem mais próximo daquele do que deste, situa-se o Camilo dramaturgo, cujo labor enquanto tal se manteve constante ao longo da sua vida de forçado das letras - como de si próprio se dizia. (REBELLO, 2001, p.6)

E encerra a introdução que fez ao livro, creditando-lhe o seguinte louvor "Mas the bastariam as três peças agrupadas neste volume para lhe granjear um lugar irremovivel na história da literatura dramática portuguesa."(REBELLO, p.20).

Camilo, ao escrever - mesmo em cadeias - libertava-se e prendia os seus algozes. O clímax do teledrama se dá exatamente quando a liberdade lhe é tirada pela cegueira.

A mesma mão que escreveu alucinadamente durante toda uma vida é a que determina o seu fim. Usando da mínima autonomia de que ainda dispunha, depois de escrever uma verdadeira biografia que subjaz em sua obra, o escritor Camilo Castelo Branco determina, ele mesmo, o seu último ato que no teledrama não fora mostrado, mas resgatado nesta réplica épica de Ana Plácido que finaliza Todo o amor é amor de perdição.

CAMILO (voz "off»): As personagens de minha comédia foram caindo, uma a uma, no palco onde eu já mal podia andar.

(...)

CAMILO (voz "off»): O peito inclinado sobre uma banca escrevia e suava sangue para ganhar o pão duma família. $\mathrm{E}$ a luz dos meus olhos esvaindo-se na cegueira. Tudo trevas à minha volta! (pausa) Eu tinha jurado: "se fico cego, mato-me!».

(Ouve-se um tiro.)

ANA PLÁCIDO (voz "off»): Às 3 da tarde do dia 1 de junho de 1890, trinta anos depois do dia em que entrei na Cadeia da Relação, um tiro ressoou no silêncio de $\mathrm{S}$. Miguel de Seide, onde vivíamos desde a morte de Manuel Pinheiro Alves. O corpo sem vida de Camilo baloiçava na cadeira de repouso, um fio de sangue a escorrer da fonte direita.

Como ele um dia disse, todo o amor é amor de perdição... (REBELLO, 1994, p.112-113) 
À semelhança de muitos desfechos camilianos de romances e peças, o desfecho dado por Rebello ao teledrama tangencia o melodrama e o aproxima, ainda mais, do estilo camiliano de solucionar os triângulos amorosos com a morte fatídica do protagonista.

\section{Referências bibliográficas}

CAMOCARDI, E. Camilo: "Biografismo e novelística." In: Estudo Geral. Avaré: Faculdade de Filosofia, Ciências e Letras, vol.1, 1973.

CASTElO BRANCO, C. Amor de Perdição. 11. ed. São Paulo: Ática, 1988.

. Teatro: Patologia do Casamento, O Morgado de Fafe em Lisboa, O Condenado. Lisboa: Parceria Antônio Maria Pereira Livraria Editora, 1991.

O último acto. Lisboa: Parceria A. M. Pereira, 1971.

MENDONÇA, F. Para o estudo do teatro em Portugal (1946-1966), Assis:

Faculdades de Filosofia, Ciências e Letras, 1971.

REBELlO, L. F. O teatro de Camilo. Lisboa: Instituto de Cultura e Língua Portuguesa, 1991.

. "Introdução" In: CASTELO-BRANCO, C. Teatro: Patologia do casamento, $O$ morgado de Fafe em Lisboa, O condenado. Lisboa: Parceria Antônio Maria Pereira Livraria Editora, 1991, p.5-20. . Todo o amor é amor de perdição: o processo de Camilo e Ana Plácido. Teledrama em 3 partes. Lisboa: Sociedade Portuguesa de Escritores, Publicações Dom Quixote, 1994. 